\title{
Aprendizagem da docência em grupo colaborativo: histórias infantis e matemática
}

\author{
Ana Paula Gestoso de Souza' \\ Rosa Maria Moraes Anunciato de Oliveira'
}

\section{Resumo}

Investiga-se de que maneiras o processo de elaboração, análise e utilização de um material educativo desenvolvido em um grupo com características colaborativas pode se configurar como fonte de aprendizagem da docência na formação inicial no curso de Pedagogia, analisando-se o processo de aprendizagem da docência das participantes, os conhecimentos mobilizados e as dificuldades enfrentadas. Para tanto, optou-se pelo estudo de caso da Atividade Curricular de Integração Ensino, Pesquisa e Extensão (Aciepe) intitulada Histórias Infantis e Matemática nas Séries Iniciais do Ensino Fundamental e tomaram-se como dados os depoimentos de cinco egressas do curso de Pedagogia sobre o processo vivido ao estudarem referenciais que abordavam a língua materna, a linguagem matemática, o ensino de matemática e a conexão entre literatura infantil e matemática, bem como ao construírem e implementarem livros infantis com conteúdos matemáticos. Foram utilizadas múltiplas fontes de dados, tais como: diversos registros escritos elaborados ao longo da atividade de pesquisa, ensino e extensão (relatórios, planos de aula, diários de campo, livros produzidos etc.), entrevistas e questionários respondidos após o término da Aciepe. Os resultados, cuja análise possibilitou discutir as potencialidades de materialização de um espaço para elaboração, análise e utilização de materiais educativos, permeado pela discussão coletiva entre graduandos, professores em exercício e formadores de diferentes áreas, apresentam as aprendizagens da docência referentes às dimensões pessoal e profissional das participantes.

\section{Palavras-chave}

Formação de professores - Formação inicial - Grupo colaborativo - Material educativo - Curso de Pedagogia.

I- Universidade Federal de São Carlos, São Carlos, SP, Brasil.

Contatos: ana_gestoso@yahoo.com.br; rosa.ufscar@gmail.com 


\title{
Learning of teaching in a collaborative group: children's stories and mathematics
}

Ana Paula Gestoso de Souza'

Rosa Maria Moraes Anunciato de Oliveira'

\begin{abstract}
This study examines the ways in which the process of preparation, analysis and use of educational material developed in a group with collaboration features can be a source of learning of teaching in initial training in the Education course, analyzing the participants' process of learning how to teach, the knowledge mobilized and the difficulties faced. To this end, we chose the case study of Atividade Curricular de Integração Ensino, Pesquisa e Extensão (Aciepe Curricular Activity for the Integration of Teaching, Research and Extension) titled Histórias Infantis e Matemática nas Séries Iniciais do Ensino Fundamental (Children's Stories and Mathematics in the early grades of Primary Education) and collected data from the reports of five recent grads of the Education course on the process experienced when studying references that addressed the mother tongue, the language of mathematics, teaching mathematics and the connection between children's literature and mathematics, as well as when building and using children's books with mathematical content. We used multiple data sources, such as various written records developed during the research, teaching and extension activities (reports, lesson plans, field journals, books produced etc.), interviews and questionnaires answered after completion of Aciepe. Research results present the learning of teaching related to the participants' personal and professional dimensions. The analysis of those results allowed discussing the potential establishment of a space for the preparation, analysis and use of educational materials. Such space should be permeated by collective discussion among students, practicing teachers and trainers from different areas.
\end{abstract}

\section{Keywords}

Teacher education - Initial training - Collaborative group Educational material - Education course.

I- Universidade Federal de São

Carlos, São Carlos, SP, Brasil.

Contact: ana_gestoso@yahoo.com.br;

rosa.ufscar@gmail.com 
Como parte de uma pesquisa de doutorado, buscou-se investigar, sob a perspectiva de egressas do curso de Pedagogia, as contribuições da Atividade Curricular de Ensino, Pesquisa e Extensão (Aciepe) intitulada Histórias Infantis e Matemática nas Séries Iniciais do Ensino Fundamental, voltada para o desenvolvimento do processo de aprender a ensinar matemática. A Aciepe, ofertada entre os anos de 2004 e 2010, teve como público-alvo os estudantes dos cursos de Licenciatura em Pedagogia e de Licenciatura em Matemática, além de professores da Educação Básica, e propunha as seguintes atividades: o estudo de referenciais que abordavam a língua materna, a linguagem matemática, o ensino de matemática e a conexão entre literatura infantil e matemática, bem como a análise, a construção e a implementação de livros infantis com conteúdos matemáticos.

Neste artigo, investiga-se de que maneiras o processo de analisar, construir e utilizar um material educativo desenvolvido em um grupo com características colaborativas pode se configurar como fonte de aprendizagem da docência de futuras pedagogas, analisando-se o processo de aprendizagem da docência das participantes, os conhecimentos mobilizados e as dificuldades enfrentadas. Para tanto, foram utilizados como dados os depoimentos de cinco participantes sobre o processo percorrido ao cursarem a Aciepe.

\section{Formação inicial e aprendizagem da docência}

Este trabalho se embasa na perspectiva da formação docente como um contínuo, isto é, algo que começa nas experiências de vida escolar e compreende toda a trajetória do docente, perpassando por diversas fases até o final de sua carreira.

Nessa trajetória, a formação inicial possui um papel fundamental, pois é o começo da socialização profissional docente e não deve ofertar apenas uma formação de um técnico acrítico que desenvolve situações de ensino e aprendizagem sem responsabilidade social e política. No tipo de formação defendida por Imbernón (2004), o professor, dotado de um arcabouço de conhecimentos científicos, culturais, contextuais, psicopedagógicos e pessoais, será capaz de analisar e investigar as situações educativas, tendo ciência das funções educativas, das consequências de suas decisões e do contexto social, histórico e político em que a prática escolar se insere. Sendo assim, esse docente conseguirá compreender as mudanças que ocorrem no espaço escolar e adequar o processo de ensino e aprendizagem às necessidades formativas dos estudantes.

Na perspectiva de Gatti (2009), duas dimensões devem ser consideradas na formação docente: uma formação cultural que possibilite a compreensão da educação e do ensino; e uma formação que verse sobre os conhecimentos e o entendimento do sistema escolar e da escola como um sistema sociocultural com especificidades. Assim, os professores "precisam ser instrumentalizados para lidar com o ensino, que é o foco de sua profissão, e o elemento defınidor de sua profissionalização" (GATTI, 2009, p. 100). Para a autora, considerar esses elementos pode possibilitar a formação de um docente com espírito investigativo, que domine conhecimentos teóricos e práticos da didática e das práticas de ensino conectados aos conhecimentos disciplinares e interdisciplinares.

Nesse sentido, destaca-se a importância de o futuro professor estabelecer um contato com a prática pedagógica. Tal contato exige planejamento e orientação, pois a qualidade da experiência vivida depende de como o docente em formação pensa sobre ela. Trata-se de um pensar sobre que, segundo Zeichner (1993), não envolve apenas técnicas e estratégias de ensino e nem ocorre apenas na esfera individual. 0 autor também alerta para a importância de o graduando aprender com as experiências de mais de um professor e vivenciar os domínios escolares e comunitários do trabalho docente, afirmando ser fundamental que os professores se assumam como formadores do futuro professor 
e superem a frágil relação entre o supervisor universitário e o professor da escola.

Diante do exposto, observa-se a relevância da formação inicial. Na formação almejada, as disciplinas acadêmicas possuem valor na medida em que podem possibilitar a aquisição de conhecimentos para a análise da prática escolar, além de permitir certo contato com a prática pedagógica, bem como sua investigação e sua compreensão, reelaborando e aprofundando as teorias e os saberes da experiência. Pretende-se uma formação inicial que forneça condições para que o futuro professor conecte sua análise sobre a prática com outros aspectos da educação, como as dimensões éticas e morais, para que reflita sobre os estudantes e seu ensino, considerando o contexto social e institucional que influencia a prática escolar, e para que valorize os espaços para discussões coletivas.

No presente trabalho, considera-se que esse tipo de formação provê elementos para a construção do que Shulman (2004) e colaboradores denominam base de conhecimento para ensinar. Ela envolve conhecimentos de diferentes tipos e origens, compreensões, habilidades e disposições que possibilitam que o docente desenvolva situações de ensino e aprendizagem em diferentes contextos educacionais, níveis e modalidades de ensino e áreas de conhecimento.

Diante das ideias de Shulman (2004) e seus colaboradores, Mizukami (2004) enfatiza que a base de conhecimento pode ser agrupada em: conhecimento pedagógico geral, conhecimento do conteúdo específico e conhecimento pedagógico do conteúdo.

A categoria conhecimento pedagógico geral envolve conhecer os alunos; as teorias sobre os processos de ensino e aprendizagem; os contextos e fins educacionais; as políticas públicas e os programas educacionais; os fundamentos históricos e filosóficos da educação; o currículo; as diferentes metodologias de ensino; as formas como as matérias podem ser abordadas pelo uso de livros didáticos, das propostas curriculares, dos softwares etc.
Por outro lado, o conhecimento do conteúdo especifico abrange as compreensões de fatos, conceitos, processos e procedimentos de uma área específica. De acordo com Shulman (2004), o professor precisa compreender o que e o porquê dos conhecimentos, fenômenos e saberes. Ou seja, não é suficiente que o docente saiba definir conceitos, mas ele deve conhecer a estrutura de determinada área de conhecimento, saber as formas de organização dos conteúdos dentro dessa área, conhecer a importância e as relações que eles podem estabelecer entre si e com outras áreas do conhecimento.

A conexão entre essas duas categorias resulta no conhecimento pedagógico do conteúdo. Para Shulman (2004), é fundamental que o professor, além de conhecer o conteúdo específico, saiba utilizar os diferentes modos de representação de um conceito e/ou de uma ideia, como analogias, exemplos, explicações, ilustrações etc. Além disso, ele deve ter conhecimentos sobre como os alunos aprendem determinados conteúdos, as dificuldades que enfrentam nesse processo e seus conhecimentos prévios acerca dos assuntos e tópicos ensinados. Também se inclui nessa categoria conhecer os aspectos que facilitam e/ou dificultam a compreensão de determinado conteúdo.

Segundo Mizukami (2004), o docente pode estabelecer uma relação de protagonismo com o conhecimento pedagógico do conteúdo, pois ele constrói e reconstrói esse conhecimento ao ensinar. Assim, "este conhecimento é a categoria que diferencia o especialista em conteúdo do educador" (MIZUKAMI, 2004, p. 10). De acordo com a autora, tal conhecimento é aprendido no decorrer do exercício profissional, mas não está desconectado do que o professor aprende nos cursos, nos programas e no estudo das teorias. Além disso, a autora afirma que o conhecimento pedagógico do conteúdo deve estar presente nos cursos de formação inicial como objeto de estudo. 


\section{A Aciepe Histórias Infantis e Matemática nas Séries Iniciais}

A Atividade Curricular de Integração Ensino, Pesquisa e Extensão (Aciepe) é uma proposta da Universidade Federal de São Carlos (UFSCar) que envolve professores, técnicos e alunos da universidade, bem como outros sujeitos da sociedade, visando articular ensino, pesquisa e extensão, e que pode ser oferecida por qualquer departamento da universidade, sob a coordenação de um ou mais professores responsáveis. Além disso, conta com apoio financeiro da Pró-Reitoria de Extensão da UFSCar na compra de material de consumo e permanente, no pagamento de pessoa jurídica, na compra de passagens para palestrantes externos e na concessão de bolsas de monitoria para os graduandos da instituição no âmbito de projeto aprovado pelo Conselho de Extensão da universidade. ${ }^{1}$

\section{A Aciepe Histórias Infantis e Matemática} nas Séries Iniciais foi ofertada entre 2004 e 2010, sob a coordenação das professoras Carmen Lúcia Brancaglion Passos e Rosa Maria Moraes Anunciato de Oliveira. Tinha como públicoalvo estudantes dos cursos de Pedagogia e de Licenciatura em Matemática, além de professores da Educação Básica, e desenvolveu as seguintes atividades: estudo teórico e discussão com o grupo de referenciais que abordavam a língua materna, a linguagem matemática, as potencialidades da leitura, o ensino de matemática e a conexão entre literatura infantil e matemática; análise, construção e posterior aplicação de livros infantis com conteúdos matemáticos. É importante ressaltar que o processo de criação era socializado com o grupo, fato que permitiu que os participantes (graduandos, professores e acadêmicos) compartilhassem experiências e saberes, traçassem objetivos para mudanças e tecessem sugestões. Além disso, o livro produzido era analisado pelo colega por meio de um parecer escrito.

1- Mais informações sobre a Aciepe estão disponiveis em: <http://www2. ufscar.br/interface_frames/index.php?link=http://www. proex.ufscar.br> Acesso em: 26 jul. 2013.
Nesse cenário, as características do trabalho colaborativo da Aciepe e a proposta aos participantes de produzirem um livro infantil, isto é, um material educativo, são aspectos que merecem ser analisados mais atentamente. Faz-se necessário, então, conceituar o termo colaboração. Para tanto, retoma-se Hargreaves (1998), que apresenta os seguintes aspectos do trabalho colaborativo: voluntariedade, identidade, espontaneidade, liderança compartilhada ou corresponsabilidade, apoio e respeito mútuo. Fiorentini (2004) aponta outros aspectos do grupo colaborativo, os quais, de certa forma, são envolvidos pelas características assinaladas por Hargreaves (1998): ação e reflexão compartilhadas, diálogo, negociação, confiança mútua, entre outros.

As relações do grupo colaborativo não são reguladas por agentes exteriores; as responsabilidades são negociadas e o grupo defıne quem irá coordenar as atividades, bem como acorda as tarefas a serem realizadas e as finalidades das ações de cada um. Assim sendo, os participantes se identificam porque podem compartilhar problemas, vivências e objetivos de interesse comum. Tal interesse comum, porém, não signifıca que não haja perspectivas e compreensões diferentes entre os participantes do grupo diante de uma mesma situação. A concretização de um grupo colaborativo não é um processo simples e fácil de ser percorrido, por isso é fundamental o apoio intelectual, técnico ou afetivo - mútuo entre os participantes. Estudos como o de Ferreira (2006) e o de Nacarato et al. (2006), entre outros, mostram que os grupos colaborativos facilitam e estimulam o desenvolvimento profissional, propiciando a aprendizagem dos professores.

No caso da Aciepe, além de possuir algumas das características elencadas anteriormente sobre a colaboração, a atividade também tem como aspecto positivo a parceria entre professores da educação básica, alunos da graduação e da pós-graduação, pesquisadores e professores da universidade. De acordo com Ferreira (2006) e Nacarato et al. (2006), a parceria beneficia todos 
os participantes, em razão de esses sujeitos se unirem para estudar e compartilhar saberes e experiências, e a união provavelmente acontece por suas diferenças de perspectivas em relação à prática pedagógica. Ressalta-se que tais diferenças não significam supervalorização de uma perspectiva em detrimento de outra.

Outro elemento importante considerado nesta investigação é o fato de os participantes da Aciepe produzirem um material educativo. Davis e Krajcik (2005) afırmam que os materiais educativos curriculares são capazes de ajudar o educador tanto a aprender, como também a antecipar e a interpretar o que os alunos podem pensar sobre determinado conteúdo ou fazer em resposta às atividades de ensino propostas.

Os materiais educativos ainda se configuram como um apoio adicional para que o professor desenvolva o conhecimento pedagógico do conteúdo, pois são um suporte para o conhecimento sobre as representações de um conteúdo específico, tais como as analogias, os modelos, os diagramas, entre outros. Tais materiais também podem proporcionar a compreensão dos fatos e conceitos sobre os conteúdos específicos e conectar as temáticas que envolvem essas matérias e que são abordadas ao longo de determinado período do ano letivo.

Davis e Krajcik (2005) ainda ressaltam que os materiais curriculares possibilitam que os professores atentem para as ideias subjacentes que orientam suas ações, promovendo certa autonomia docente e auxiliando-os a tomarem decisões sobre como adaptar as matérias do currículo às determinadas características dos alunos e aos contextos de ensino. De acordo com os autores, entretanto, a eficácia dos materiais educativos curriculares na promoção da aprendizagem docente pode ser limitada por pelo menos três fatores que devem ser superados: 1) a falta de qualidade em termos de conteúdo e de conhecimento pedagógico presente nos materiais; 2) a limitação da eficácia dos materiais em razão das características dos próprios professores, de seus conhecimentos, de suas crenças e disposições para reflexão e melhoria de sua própria prática; 3) a utilização sozinha, muitas vezes, desses materiais educativos curriculares.

Tendo por base as perspectivas de tais autores, Oliveira e Passos (2008, p. 318) afirmam que "a construção de materiais que auxiliem nesse desenvolvimento profissional parece um promissor campo de investigação e de formação" e alertam que tanto a construção quanto a utilização de materiais pedagógicos não devem ser consideradas como uma solução milagrosa.

\section{O processo de pesquisa}

A presente investigação aproximou-se da estratégia de estudo de caso, pois considera alguns dos elementos dessa vertente e referenda as ideias de André (1984, 2005), para quem o objetivo do estudo de caso é compreender a situação como ela é realmente. Trata-se de uma pesquisa sobre uma unidade específica, situada em determinado contexto. Por isso, uma das vantagens desse tipo de estudo é que ele propicia uma visão aprofundada, ampla e integrada da unidade investigada, que é composta por múltiplas variáveis, permitindo considerar sua complexidade e sua dinâmica natural. Em razão disso, essa abordagem metodológica exige o uso de duas ou mais fontes de evidência para a coleta de dados.

0 interesse pelo particular, uma das características mais distintivas do estudo de caso, não implica perder a noção do todo e desvincular o caso do contexto, pois "uma apreensão mais completa do objeto só é possível se for levado em conta o contexto no qual este se insere" (ANDRÉ, 1984, p. 52). Portanto, devem ser considerados todos os aspectos que envolvem o caso estudado.

Além disso, o estudo de caso possibilita que seja feita uma generalização naturalística, a qual se "desenvolve no âmbito do indivíduo e em função de seu conhecimento experiencial" (ANDRÉ, 1984, p. 52). A partir da leitura, da descrição densa do caso, do contexto, dos sujeitos e das relações que esses elementos estabelecem, o leitor indagará e decidirá se as interpretações, 
ideias e hipóteses apresentadas no estudo podem ser aplicadas à sua situação de interesse.

Considerando-se as características e os pressupostos apresentados sobre o estudo de caso, optou-se por utilizar essa abordagem metodológica para investigar de que maneiras o processo de analisar, construir e utilizar um material educativo, permeado por características de um grupo colaborativo, pode se configurar como fonte de aprendizagem da docência de futuras pedagogas, analisando-se o processo de aprendizagem das participantes, os conhecimentos mobilizados e as dificuldades enfrentadas. Assim sendo, a Aciepe foi o caso analisado e as histórias das participantes configuram-no.

As especificidades do processo investigado referem-se ao fato de que as aprendizagens proporcionadas pela Aciepe ocorreram em um contexto de formação com uma dinâmica e características específıcas, concretizado pelo suporte da instituição formativa. Além disso, as aprendizagens não são iguais para todas as participantes, pois possivelmente cada uma se apropriou e mobilizou os conhecimentos de forma particular.

Foram contatadas nove das 18 egressas do curso de Pedagogia que participaram da Aciepe entre 2004 e 2010, em razão de elas terem utilizado o livro elaborado na atividade curricular em situações de ensino e aprendizagem na graduação. Dentre elas, cinco aceitaram participar da pesquisa.

Como fontes de coleta de dados, utilizaram-se os registros existentes, elaborados pelos estudantes do curso de Pedagogia que participaram da Aciepe no período indicado, tais como: diário da elaboração do livro, esboços dos livros, os livros produzidos, plano de ensino para a utilização dos livros em sala de aula, diário reflexivo e relatório das aulas, entre outros registros produzidos pelos participantes. Além disso, realizou-se uma entrevista estruturada e foram aplicados questionários abertos às participantes da pesquisa após o término da Aciepe. Outra fonte de coleta de dados foi o trabalho de conclusão de curso de uma das egressas, que buscou investigar suas aprendizagens ao cursar a atividade de extensão.

Após o retorno de um questionário, ele era analisado, privilegiando-se os acontecimentos mais significativos em relação aos objetivos da investigação, e elaborava-se um novo roteiro de questões com a finalidade de aprofundar e/ou esclarecer as respostas apresentadas. Cada participante respondeu de três a quatro questionários, gerando dados para compreender a aprendizagem da docência na atividade de ensino, pesquisa e extensão, identificando-se os saberes, as perspectivas e as motivações das participantes.

No período de coleta dos dados (entre 2010 e 2011), as participantes atuavam na área de educação e estavam em início de carreira. Ana, Thaís, Daiana e Marcela exerciam função docente nos anos iniciais do ensino fundamental e Maria Luiza atuava como assistente de coordenação e professora substituta. Os nomes dessas quatro participantes são fictícios e foram escolhidos por elas. Uma participante disse que gostaria que fosse utilizado seu nome verdadeiro.

\section{As participantes e os livros elaborados}

Ana participou da Aciepe nos anos de 2008 e 2009, para buscar aprofundar seus conhecimentos sobre o ensino de matemática, e elaborou dois livros: Papai Noel existe! Mas já não se lembra mais e Herlock Sholmes - e o famoso caso do Papai Noel. Em ambos os enredos, o Papai Noel sofre um atentado que gera uma série de dúvidas em relação ao criminoso e o leitor é convidado a descobrir quem é o autor do crime. 0 primeiro livro apresentava três desfechos e, ao final de cada um deles, havia vários problemas matemáticos para o leitor resolver. Os conteúdos dos problemas propostos foram: proporção, adição, subtração, multiplicação, dobro, metade e porcentagem. No segundo livro, o detetive Herlock Sholmes precisava resolver alguns problemas matemáticos apresentados ao longo da história, e o leitor é convidado para ajudá-lo a solucioná-los. Os conteúdos dos problemas 
foram: leitura de gráficos, proporção, adição, subtração, multiplicação, dobro, metade, porcentagem, fração e lógica.

Thaís, em 2005, escolheu cursar a Aciepe pelo fato de gostar de matemática e elaborou o livro Por que aprender matemática?, no qual Pedrinho, o personagem principal - que considerava matemática uma disciplina difícil -, precisou resolver dois problemas matemáticos que abordavam os conceitos de dúzia, dezena e adição. Um dos problemas foi solucionado em uma feira livre e o outro, no sítio de sua avó. No final da narrativa, Pedrinho mostrou para a professora que conseguiu concluir a tarefa e aprender os conteúdos.

Daiana, em 2006, buscou participar da Aciepe para aprofundar seus conhecimentos sobre o ensino de matemática e elaborou o livro A cara quadrada. No início do enredo, o quadrado estava triste, pois não conhecia outros quadrados. 0 cubo tentou animá-lo explicando que ele é formado por quadrados e, no decorrer da história, apresentou-lhe outras formas geométricas. 0 conteúdo matemático abordado no livro envolve as características e propriedades das seguintes formas geométricas planas e espaciais: quadrado, triângulo, retângulo, círculo, cubo, pirâmide, esfera e bloco retangular. Ao final do livro, foram apresentadas atividades para o leitor resolver.

Maria Luzia, em 2006, escolheu participar da Aciepe pois se sentiu motivada a escrever um livro e elaborou a história Uma tarde na marcenaria, que tem Paulo como personagem principal. No enredo, a professora de Paulo propôs aos alunos que observassem objetos e figuras e atentassem para situações que envolvessem a geometria. A partir disso, Paulo e seu amigo desenvolveram um olhar observador aos objetos e, ao observarem o pai de Paulo construir uma cadeira, aprenderam algumas propriedades das formas geométricas. Os conteúdos matemáticos abordados na narrativa envolveram as propriedades das seguintes formas geométricas: círculo, retângulo, quadrado, cilindro e triângulo isósceles. As ilustrações são um auxílio na compreensão da história e do conceito matemático abordado.

Marcela, no ano de 2005, decidiu participar da Aciepe por considerar interessante a metodologia de ensino proposta. Elaborou e aplicou o livro Uma casa nem tão mal assombrada, que narra a história de um grupo de amigos que entrou em uma casa aparentemente mal assombrada e lá descobriu que a dona era uma simpática senhora, que lhes serviu um lanche com bolos e tortas. 0 conteúdo abordado no livro foi a noção de fração como subconstruto parte-todo e a soma de frações que possuem o mesmo denominador.

\section{Elaborando e utilizando histórias infantis com conteúdos matemá- ticos: aprendizagens da docência em} um grupo colaborativo

A análise dos dados indica que a Aciepe contribuiu para o desenvolvimento das dimensões pessoal e profissional das participantes da pesquisa. Diante disso, retoma-se a perspectiva de Mizukami (2006), para quem o desenvolvimento profissional docente engloba três processos: o desenvolvimento pessoal, o da profissionalização e o da socialização profissional.

0 desenvolvimento pessoal, para Mizukami (2006), refere-se ao crescimento individual que incorpora capacidades, personalidade, habilidades e interação com o ambiente. Com relação a esse desenvolvimento, podem-se destacar as seguintes aprendizagens na Aciepe: saber ouvir, pedir ajuda, ter humildade ao errar, buscar superar o erro e ser paciente. No processo de aprendizagem das participantes na Aciepe, o erro não foi considerado como uma punição ou algo a ser ignorado, mas foi problematizado e se tornou uma situação de aprendizagem. Os trechos dos depoimentos apresentados a seguir, reproduzidos na íntegra, ilustram essas aprendizagens:

Aprendi a pedir ajuda. Aprendi a errar e a tentar acertar de novo. Aprendi a ouvir opiniões. Aprendi que não é fácil ser professor. 
Aprendi que nem tudo sai como o planejado, e que no planejamento até os imprevistos são pensados. [...] [Aprendi a] revisar o que foi feito com o intuito de fazer melhor para a próxima vez. (Entrevista de Ana)

Aprendi a pedir ajuda sem vergonha de dizer que não sei algo [...] a ler, escrever, ler, reescrever, ler, reescrever, até perder as contas! [...] Aprendi a ter paciência e a falar a mesma coisa de diversas maneiras. A lidar com as dificuldades que sempre aparecem. (Questionário de Maria Luzia)

Também é importante destacar que a experiência de entrar em contato direto com a prática pedagógica possibilitou que Ana aprendesse um dos elementos de satisfação da profissão docente: a aprendizagem do aluno. Isso foi descrito por ela como um fato marcante em sua trajetória, o que é possivel observar no relato a seguir.

Poder produzir uma aula pensando única e exclusivamente nos alunos que irão trabalhar com este material foi uma experiência a qual me permitiu decidir de fato que é exatamente isso que eu quero fazer para o resto da minha vida. (Entrevista de Ana)

Ao analisar o desenvolvimento profissional das participantes, constatam-se aprendizagens relacionadas aos elementos da base de conhecimento para a docência.

No que concerne ao conhecimento pedagógico geral, podem ser verificadas, nos depoimentos de Ana, Thaís e Marcela, aprendizagens sobre elementos que fazem parte do planejamento docente. São aprendizagens que se conectam com a ideia de que os objetivos de ensino e as expectativas de aprendizagem devem estar claros para o professor, portanto a ausência do planejamento acarreta a improvisação, prejudica a aprendizagem dos alunos e o trabalho docente. Como exemplo, apresentamse trechos dos relatos de Ana e de Thaís:
[Ao utilizar o livro] pude experimentar um pouco do que é ser professor de fato. Pude ter contato com todo o processo de preparar uma aula pensando nos vários fatores que envolvem preparar uma aula: pensar na idade dos alunos, em atividades apropriadas, no tempo gasto, pensar inclusive em possiveis imprevistos e se preparar para eles. Quanto ao tempo, percebi que por mais que se estipule um tempo "x" este depende única $e$ exclusivamente da turma na qual a aula será ministrada. (Entrevista de Ana)

Para ministrar uma aula não devemos nos atentar somente nas horas em que esta está se concretizando. [...] o(a) professor(a) precisa elaborar um plano. Na elaboração deste [plano] percebi a importância de relacioná-lo aos textos estudados, para que não ficasse incoerente; com base nestes destaquei os objetivos, os conteúdos matemáticos, a metodologia de ensino, as atividades a serem desenvolvidas referentes à narrativa, os recursos materiais e a avaliação. (Plano de ensino elaborado por Thaís)

Essas aprendizagens mostram importantes contribuições da Aciepe, pois, segundo Veenman (1988), uma das dimensões para a qual a formação inicial precisa se voltar é a aprendizagem de planejar, que envolve: aprender a elencar os objetivos das aulas, saber quais atividades devem ser realizadas e quais flexibilizações podem ser feitas; atentar para as características específicas do aluno, para as formas de gerenciamento das aulas e para as práticas avaliativas.

Especificamente sobre 0 processo percorrido, ao implementar situações de ensino a partir dos livros que elaboraram na Aciepe, verificou-se que as participantes vivenciaram alguns percalços, tais como: dificuldades em controlar a ansiedade de ministrar uma aula; gerenciar a sala de aula e, principalmente, controlar o comportamento do aluno; adequar corretamente o tempo da aula; e lidar com acontecimentos 
inesperados. Os relatos apresentados a seguir ilustram essas considerações:

Foi muito difícil fazer um plano de aula que tivesse apenas algumas horas de duração. Primeiro porque as questões propostas no livro possibilitam uma infinidade de respostas, todas corretas e eu poderia passar dias explicando porque estão todas certas; E depois porque eu consigo visualizar, durante a história, muitos assuntos, questões e temas referentes a outras disciplinas que também poderiam ser trabalhados em aulas interdisciplinares. (Trabalho de Conclusão de Curso de Ana)

A dificuldade inicial que encontrei foi em como dar atenção a todos os alunos, pois nessa idade todos querem falar e acabam falando ao mesmo tempo. [...] É por isso, que quando fazia alguma pergunta esperava a resposta de todos ou ia de grupo em grupo. Assim tinha certeza de que todos estavam acompanhando a aula. (Relatório de Marcela sobre a utilização do livro)

No desenvolvimento da história os alunos se mostraram interessados e houve silêncio, com exceção de um grupo, o qual se dispersava e a todo momento perdia a sequência da história e não conseguia acompanhar pelo livro. (Relatório de Thaís sobre a utilização do livro)

Diante do cenário que baliza os anos iniciais do exercício docente, Veenman (1988) aponta alguns elementos que precisam ser enfocados nos cursos de formação inicial e que permitem ao futuro professor desenvolver uma gama de saberes e competências necessárias para lidar com as dificuldades que são características dessa fase, objetivando diminuir o choque com a realidade: a gestão da classe, o saber escutar, o compreender, o conhecer as diferentes formas de respostas que os alunos podem dar tendo em vista a abordagem de determinado conteúdo e o saber avaliar.
Continuando a análise das trajetórias das participantes, também foi possível verificar que elas se mobilizaram para aprender o conteúdo matemático abordado em seus livros. Para isso, estudaram e buscaram ajuda dos participantes e formadores da Aciepe e também de outros colegas. Os excertos seguintes ilustram tal afırmação:

0 estudo do conteúdo foi ótimo pra mim, pois descobri conceitos novos que antes não conhecia. (Questionário respondido por Daiana)

Estudei por vários livros o conteúdo matemático, descobri muitos erros, questionei alguns amigos que faziam o curso de matemática na engenharia, eles me ajudaram muito e deram ótimas ideias. (Questionário respondido por Maria Luiza)

Procurei ajuda de alguns amigos da ACIEPE e amigos de outros cursos [...] [Eles] me ajudaram ouvindo minhas angústias sobre as dificuldades que encontrava e sempre davam palpites para melhorar o enredo, a forma como iria expor o conteúdo e palavras de motivações dizendo que era capaz. (Questionário respondido por Marcela)

As participantes relataram ter aprendido também conteúdos matemáticos abordados nos livros dos colegas. Ana, por exemplo, afirmou que as discussões foram importantes para a aprendizagem dos conteúdos matemáticos não apenas de seu livro, pois, ao tomar contato com um livro elaborado por um colega, percebeu que aprendera "o teorema de Pitágoras de forma diferente" (Ficha de avaliação da Aciepe, 1 jul. 2008). Em razão dessa aprendizagem, ela destaca a importância de os alunos do curso de matemática também participarem da Aciepe.

Outra contribuição da Aciepe se refere à aprendizagem do conhecimento pedagógico do conteúdo. As participantes declararam que a Aciepe possibilitou que elas entrassem em contato 
com estratégias de ensino que efetivamente motivam o aluno e são interessantes para ele. Ou seja, parece que a literatura foi considerada por elas como um elemento motivador que proporciona que o aluno tenha vontade de realizar as atividades.

Uma maneira interessante de ensinar matemática é através da literatura, pois incentiva, motiva e envolve os alunos, levando a uma constante busca de soluções para problemas que tenham real significado para eles, deixando de lado toda atividade que vise à memorização sem compreensão. (Plano de aula elaborado por Thaís)

A aula se torna mais divertida, eles prestam bastante atenção na leitura e o diálogo fica enriquecido. (Questionário respondido por Marcela)

Observei que os estudantes, no geral, aprendem uma matemática dura e estática, ausente de significações para o sujeito enquanto construtor do conhecimento, no entanto, percebi que alguns recursos, como a literatura, podem ajudá-los e tornar esse aprendizado mais efetivo e duradouro. (Trabalho de Conclusão de Curso de Ana)

É necessário enfatizar que esse elemento motivador é importante e faz parte da narrativa, porém, ele não é a única característica da potencialidade da proposta metodológica.

Para Daiana, Thaís, Maria Luzia e Marcela, o elemento da imaginação, presente na história, pode ser um impulsionador da aprendizagem do estudante. Segue um exemplo:

Acredito que o livro infantil proporciona à criança uma viagem pelo mundo da imaginação, incentivando a criatividade e consequentemente o aprendizado. 0 conteúdo matemático deve ser abordado de forma que as crianças sintam prazer em ler aquele livro. (Questionário respondido por Daiana)
Esse aspecto imaginário é importante, pois, segundo Dalcin (2002, p. 61-62), "no ensino e aprendizagem da Matemática, particularmente, a imaginação exerce papel fundamental nos processos de compreensão, reflexão e abstração". A mesma autora assinala que colocar os conceitos e as ideias matemáticas em um contexto, mesmo que seja uma realidade imaginária, valoriza a “observação, intuição e capacidade de análise e sintese" (DALCIN, 2002, p. 65).

Além de destacar a imaginação como um aspecto importante referente à literatura, Maria Luzia e Marcela apontaram as ilustrações como coadjuvantes para propiciar a aprendizagem dos alunos.

Esse aspecto assinalado pelas participantes também é importante, pois as ilustrações enriquecem a imaginação do leitor e, no caso da conexão literatura-matemática, podem auxiliálo a compreender um conceito ou uma ideia matemática, principalmente se o livro apresentar a articulação entre simbologia matemática, texto escrito e imagem. De acordo com Dalcin (2002), a articulação entre esses três elementos possibilita grande interação do leitor com o livro, proporcionando-lhe maior compreensão do que se lê, inclusive dos conceitos matemáticos abordados na história. Contudo, as ilustrações por si só não geram a aprendizagem, pois elas são representações dos conceitos e o aluno precisa saber transpor o que compreendeu por meio das imagens para o conceito matemático abstrato.

Além de apontarem o aspecto imaginário e as ilustrações como elementos positivos e que potencializam um ensino que articule histórias infantis e matemática, Thaís e Ana também aprenderam que essa proposta de ensino possibilita trabalhar com a resolução de problemas matemáticos.

A resolução destes [problemas] é fundamental para propor situações que requeiram uma solução matemática e que permitam o levantamento de questões, pesquisa, discussão, exploração e especulação, além da contextualização 
das operações. Cabe ao professor criar problemas significativos, situações que desafiem o aluno e que possui várias estratégias e métodos de resolução que levem o aluno a agir na construção do conteúdo, buscando os conhecimentos anteriores que auxiliam na resolução. (Plano de aula elaborado por Thaís)

Em seu artigo, Carey (1992) mostra que a literatura infantil pode ser um rico contexto para trabalhar com resolução de problemas, pois a história permite apontar aos alunos várias questões explícitas no livro ou criadas pelo professor. A autora também afirma que, pelo fato de os problemas advirem de um contexto diferente dos livros didáticos, os alunos acabam se sentindo mais dispostos a utilizar estratégias variadas que são construídas a partir de seus próprios conhecimentos. Esse mesmo aspecto é identificado por Souza e Oliveira (2010).

Outro ponto a ser destacado são as aprendizagens referentes ao conhecimento pedagógico do conteúdo, oriundas das dificuldades que as participantes vivenciaram ao elaborar o livro, especialmente em relação à representação do conteúdo matemático, conforme é possível constatar nos depoimentos a seguir:

Gosto muito do enredo, porém o livro não saiu exatamente como eu esperava. [...] Minha ideia inicial era que as questões [os problemas] fossem sendo colocadas durante a história e que elas servissem para dar continuidade a narrativa o que obrigaria o leitor a resolvê-las. Ao propor questões no final da história não consigo imaginar como um aluno, por ele mesmo, as resolveria. Como futura professora eu posso fazer atividades com os alunos, mas ao lerem sozinhos não acredito que vão se animar muito. (Registro de Ana em seu Trabalho de Conclusão de Curso)

As maiores dificuldade foram com relação aos conceitos matemáticos abordados mesmo. Principalmente em como colocá-los de forma que as crianças entendessem. (Questionário respondido por Daiana)

Dificuldades em unir os problemas matemáticos com a narração, para que ocorra uma sequência de fatos pertinentes e que estes despertem interesse ao leitor. (Diário de campo de Thaís)

Sendo assim, pode-se inferir que, diante da dificuldade de conectar a matemática, a língua materna e o registro pictórico, as participantes se mobilizaram para perceber os diferentes modos de representar o conteúdo, para desenvolver o conhecimento de como os alunos aprendem uma matéria e para saber as dificuldades e as facilidades da aprendizagem diante de conceitos e ideias específicas, sendo que também tiveram que considerar as características dos alunos e o currículo escolar.

Enfim, os dados mostram o colocar-se em atividade dessas participantes nos momentos de estudos, discussões, elaboração e utilização dos livros. Percebe-se essa mobilização e o protagonismo das participantes no fato de elas experimentarem, questionarem, dialogarem e estudarem. 0 colocar-se em atividade é um dos elementos fundamentais para propiciar a aprendizagem docente (SHULMAN, 2004). É importante ressaltar que essa aprendizagem também depende de que o sujeito não se foque apenas no resultado, mas pense sobre $o$ processo, pois a busca por resolver os problemas enfrentados na experiência produz novas aprendizagens. Observa-se que as participantes da Aciepe engajaram-se nessa procura.

Sendo assim, é possível inferir que elaborar um material educativo permite desenvolver no professor uma atitude de estudo dos conteúdos específicos e de seu ensino, ocasionando a compreensão dos assuntos e tópicos sobre as matérias e as formas de representar os conceitos e ideias para os alunos. Observou-se que elaborar o livro possibilitou que as participantes conectassem ideias gerais e específicas, conforme 
preconizado por Davis e Krajcik (2005). Um exemplo de ideia geral poderia ser a justificativa da escolha de uma abordagem particular de ensino a ser utilizada no livro, e a ideia específica seria a abordagem instrucional de determinado conteúdo. Isso permitiu o desenvolvimento de um olhar mais atento para o planejamento das aulas e o estabelecimento de objetivos para a aprendizagem dos conteúdos ensinados.

Continuando as análises apresentadas neste artigo, faz-se necessário destacar um elemento importante que propicia o desenvolvimento profissional docente e que está presente nos depoimentos das participantes: $o$ dialogar e o compartilhar com o outro.

Ana, Daiana, Maria Luzia, Thaís e Marcela afirmaram que as discussões referentes aos estudos teóricos e o fato de haver professoras formadoras de duas áreas foram importantes para a aprendizagem de uma metodologia de ensino e para a compreensão de conteúdos específicos. Marcela, por exemplo, declarou que a "Aciepe abrange três focos: conteúdo matemático, língua portuguesa $\mathrm{e}$ didática"; para ela, abranger esses três focos é importante na formação do professor dos anos iniciais, pois eles "contemplam vertentes de aprendizagem fundamentais que um professor deve ter: conhecimentos matemáticos, metodologia para passar esses conhecimentos e uma boa escrita e fala da nossa língua”.

Isso não significa considerar cada professor como representante isolado de determinada área, mas ressaltar a importância da proposta da Aciepe, que, ao propiciar a articulação entre as áreas e envolver essas formadoras, enriquece o processo de aprendizagem do conhecimento pedagógico do conteúdo.

As participantes também assinalaram que o diálogo com estudantes da Pedagogia e da Licenciatura em Matemática possibilitou a aprendizagem de conteúdos específicos e a correção dos que foram abordados nos livros, bem como contribuiu para o enriquecimento do enredo da história criada. Além disso, esse compartilhar possibilitou que Daiana percebesse que não era a única que encontrava dificuldades com a matemática. Para Marcela, trocar experiências com o outro também serviu como motivação para superar as dificuldades encontradas ao elaborar o livro, principalmente a conexão do enredo com o conteúdo matemático escolhido. Os trechos dos depoimentos apresentados a seguir mostram a contribuição do diálogo:

A experiência foi ótima, pois pudemos perceber o quanto as dificuldades em Matemática não existiam apenas na Pedagogia, mas em outros cursos, bem como com as colegas que já atuavam na Educação Básica. Essa troca é fundamental para a formação do professor. (Questionário respondido por Daiana)

$\mathrm{Na}$ verdade fiz uma pesquisa de campo para saber que rumo dar a história, o que seria pertinente abordar, linguagem, interesse do aluno e dos pais. [...] Questionei várias mães, crianças e depois comecei a esboçar a história, embasei a história em duas crianças na faixa dos 8 anos com que eu convivia. [...] Eu conversava muito com o Roberto [nome fictício de um participante da ACIEPE] sobre o trabalho. [...] Minha irmã ajudou na criação, meu namorado, na época, me ajudou na digitalização e confecção de cada exemplar, o pai dele fez todas as ilustrações e minha mãe ajudou a pintar, meu pai ajudou na moral da história e criticou bastante! (Questionário respondido por Maria Luzia)

Nos depoimentos destacados, ainda se verifica que, para Ana, Maria Luzia e Marcela, a interação com o outro foi além da Aciepe, pois elas envolveram familiares, amigos e colegas na elaboração do livro. Ana também relatou que gostaria de criar outros livros, mas considera difícil fazer isso sem o apoio de colegas.

As participantes mostraram que a dinâmica proposta pela atividade de extensão ocorreu em um ambiente no qual houve espontaneidade, apoio intelectual, técnico 
e afetivo, respeito mútuo, ação e reflexão compartilhadas, diálogo e negociação elementos característicos de um grupo colaborativo. Cada sujeito interagiu com esses elementos de forma singular, mas a crítica construtiva e a não imposição dos participantes estiveram presentes.

Essa dinâmica da Aciepe, que favorece o diálogo, pode contribuir para romper com o isolamento característico da profissão docente e propiciar o desenvolvimento de um profissional que compartilhe com o outro seus dilemas, suas ideias e práticas e que não estabeleça uma postura de resistência às novas propostas metodológicas e a outras mudanças relacionadas aos papéis do professor e do aluno, às finalidades da educação etc. Além disso, é importante considerar que o olhar para a prática do outro, proposto por Shulman (2004), também é fonte de aprendizagem.

Os dados mostram que a relação estabelecida entre os diferentes profissionais pode concretizar o excedente de visão destacado por Fiorentini (2004). Por exemplo, os acadêmicos podem propiciar determinadas análises, interpretações e compreensões das experiências e saberes dos professores das escolas e/ou dos alunos de graduação a partir de referenciais teórico-científicos; os professores escolares, por outro lado, podem levar para o grupo saberes específicos da experiência e mostrar o que é possível ou não de se concretizar na prática escolar; o futuro professor também pode apresentar ao grupo saberes específicos, sejam os baseados nas teorias aprendidas nos cursos, sejam os relativos às vivências dos estágios e à própria conexão entre ambos, assim como contribuir no uso das tecnologias de informação e comunicação. 0 depoimento de Ana mostra esse excedente de visão:

É muito bom ouvir tanto as pessoas já formadas como as iniciantes, já que das pessoas formadas podemos "retirar" respostas e muitas vezes resolução para nossos problemas, e dos iniciantes podemos "tirar" perguntas que explicam melhor os nossos questionamentos que nem sabíamos que tínhamos. Os professores do ensino fundamental nos trazem situações reais sobre as quais podemos refletir. (Registro de Ana ao preencher a ficha de avaliação da Aciepe)

Enfım, pode-se afırmar que a dinâmica com características colaborativas propiciada pela atividade de pesquisa, ensino e extensão possibilitou que as participantes se envolvessem em um ambiente no qual puderam questionar e explorar seus saberes e suas práticas, bem como conhecer saberes e práticas de seus colegas. Elas também tiveram a possibilidade de fazer esse processo de análise a partir de referenciais teórico-científicos. Além disso, conforme foi exposto, a interlocução com o outro se colocou para além da Aciepe e se conectou com a vida pessoal das participantes.

\section{Algumas considerações}

A discussão realizada ao longo deste artigo mostrou as potencialidades de materialização de um espaço formativo para elaboração, análise e utilização de materiais educativos, permeado pela discussão coletiva entre futuros professores, professores em exercício e formadores de diferentes áreas.

Analisou-se o processo de aprendizagem da docência das participantes em uma atividade de ensino, pesquisa e extensão no curso de Pedagogia. Com relação às aprendizagens no âmbito pessoal, na perspectiva das participantes, destacam-se as seguintes: ter humildade ao errar e saber que pode precisar de ajuda e apoio tanto intelectual quanto afetivo do outro; aprender a dialogar com e a ouvir os pares; aprender a ser paciente e ter satisfação com a aprendizagem dos alunos. Assim, a dinâmica da Aciepe possibilitou que as participantes superassem aspectos de individualismo e desenvolvessem atitudes que favorecem seu desenvolvimento no grupo colaborativo. 
Quanto às aprendizagens da docência, foram destacadas aquelas referentes aos elementos que fazem parte do processo de planejamento do docente; ao conteúdo matemático; às estratégias de ensino, mais especificamente abordando determinadas características da história infantil; e à resolução de problemas matemáticos. Entre as dificuldades enfrentadas no processo, apareceram: a articulação entre o conteúdo matemático e o enredo da história, a representação do conteúdo matemático e o gerenciamento da sala de aula. As situações exigiram que as participantes, de alguma maneira, posicionassem-se diante delas e se mobilizassem para superar os obstáculos, em um movimento que possibilita ampliar saberes e habilidades do repertório de conhecimento da docência.
Sendo assim, as conclusões deste artigo permitem que sejam destacados alguns elementos a serem considerados nos cursos de formação inicial, tais como: eleger o diálogo e o trabalho com o outro como estratégias formativas, permeadas por momentos de trabalho individual; criar um espaço colaborativo permeado pelo respeito mútuo entre formadores, professores em exercício e colegas do mesmo curso ou de cursos correlacionados com as atividades a serem desenvolvidas; possibilitar momentos para análise e/ou construção de materiais educativos a serem implementados no estágio curricular, em processos de formação contínua ou outros espaços formativos; contar com apoio técnico, pessoal especializado e financiamento das agências formadoras de professores.

\section{Referências}

ANDRÉ, Marli Eliza D. Afonso de. Estudo de caso: seu potencial na educação. Caderno de Pesquisa, Rio de Janeiro, n. 49, p. 51-54, maio 1984.

Estudo de caso em pesquisa e avaliação educacional. Brasília: Líber Livros, 2005.

CAREY, Deborah A. The patchwork quilt: a context for problem solving. Arithmetic Teacher, Reston, v. 39, n. 4, p. 199-203, dez. 1992.

DALCIN, Andreia. Um olhar sobre o paradidático de matemática. Dissertação (Mestrado em Educação Matemática) - Faculdade de Educação, Universidade de Campinas, Campinas, 2002.

DAVIS, Elizabeth A.; KRAJCIK, Joseph S. Designing educative curriculum materials to promote teacher learning. Educational Researcher, Reston, v. 34, n. 3, p. 3-14, 2005.

FERREIRA, Ana Cristina. 0 trabalho colaborativo como ferramenta e contexto para o desenvolvimento profissional: compartilhando experiências. In: NACARATO, Adair M.; PAIVA, Maria Auxiliadora V. (Orgs.). A formação do professor que ensina matemática: perspectivas e pesquisas. Belo Horizonte: Autêntica, 2006. p. 149-166.

FIORENTINI, Dario. Pesquisar práticas colaborativas ou pesquisar colaborativamente? In: BORBA, Marcelo de C.; ARAUJO, Jussara de L. (Orgs.) Pesquisa qualitativa em educação matemática. Belo Horizonte: Autêntica, 2004. p. 47-76.

GATTI, Bernadete A. Formação de professores: condições e problemas atuais. Revista Brasileira de Formação de Professores, Cristalina, v. 1, n. 1, p. 90-102, maio 2009.

HARGREAVES, Andy. 0s professores em tempo de mudança: 0 trabalho e a cultura dos professores na idade pós-moderna. Portugal: MacGraw-Hill, 1998.

IMBERNÓN, Francisco. Formação docente profissional: formar-se para a mudança e a incerteza. São Paulo: Cortez, 2004. 
MIZUKAMI, Maria da Graça N. Aprendizagem da docência: algumas contribuições de L.S. Shulman. Revista do Centro de Educação da UFSM, Santa Maria, v. 29, n. 2, 2004. Disponível em: <www.ufsm.br/ce/revista/>. Acesso em: 1 ago. 2008.

. Aprendizagem da docência: conhecimento específico, contextos e práticas pedagógicas. In: NACARATO, Adair M.; PAIVA, Maria Auxiliadora V. (Orgs.). A formação do professor que ensina matemática: perspectivas e pesquisas. Belo Horizonte: Autêntica, 2006. p. 213-231.

NACARATO, Adair M. et al. Professores e futuros professores compartilhando aprendizagens: dimensões colaborativas em processo de formação. In: NACARATO, Adair M.; PAIVA, Maria Auxiliadora V. (Orgs.). A formação do professor que ensina matemática: perspectivas e pesquisas. Belo Horizonte: Autêntica, 2006. p. 197-212.

OLIVEIRA, Rosa Maria M. A. de; PASSOS, Cármen Lúcia B. Promovendo o desenvolvimento profissional na formação de professores: a produção de histórias infantis com conteúdo matemático. Ciência e Educação, Bauru, v. 14, n. 2, p. 315-330, 2008.

SHULMAN, Lee S. Those who understand: knowledge growth in teaching. In: The wisdom of pratice: essays on teaching, learning and learning to teach. 1. ed. United States of America: Jossey-Bass, 2004. p. 189-215.

SOUZA, Ana Paula G. de; OLIVEIRA, Rosa Maria M. A. de. Articulação entre literatura infantil e matemática: intervenções docentes. BOLEMA: boletim de educação matemática, Rio Claro, v. 23, n. 37, p. 955- 975, dez. 2010.

VEENMAN, Simon. El proceso de llegar a ser profesor: un analisis de la formacion inicial. In: VILLA, A. Perspectivas y problemas de la funcion docente. Madrid: [s.n.], 1988. p. 39-68.

ZEICHNER, Ken M. A formação reflexiva de professores: ideias e práticas. Lisboa: EDUCA, 1993.

Recebido em: 31.08.2012

Aprovado em: 10.06.2013

Ana Paula Gestoso de Souza possui graduação em Pedagogia pela Universidade Federal de São Carlos (UFSCar), mestrado em Educação e doutorado pela mesma universidade. Tem experiência docente nos anos iniciais do ensino fundamental. Atualmente é supervisora de tutoria e professora temporária da UFSCar.

Rosa Maria Moraes Anunciato de Oliveira é professora associada, nível 02, da Universidade Federal de São Carlos (UFSCar). Possui licenciatura em Letras e em Pedagogia pela Faculdade de Filosofia Ciências e Letras de Sorocaba, mestrado e doutorado em Educação pela UFSCar. 